\title{
Long-Term Depression at Olfactory Nerve Synapses
}

\author{
Hiroki Mutoh, Qi Yuan, and Thomas Knöpfel \\ Laboratory for Neuronal Circuit Dynamics, Brain Science Institute, The Institute of Physical and Chemical Research (RIKEN), Wako-shi, Saitama 351-0198, \\ Japan
}

The synapses formed by the olfactory nerve $(\mathrm{ON})$ convey sensory information to olfactory glomeruli, the first stage of central odor processing. Morphological and behavioral studies suggest that glomerular odor processing is plastic in neonate rodents. However, long-term synaptic plasticity, a cellular correlate of functional and structural plasticity, has not yet been demonstrated in this system. Here, we report that $\mathrm{ON} \rightarrow$ mitral cell (MC) synapses of 5- to 8-d-old mice express long-term depression (LTD) after brief low-frequency ON stimulation. Pharmacological techniques and imaging of presynaptic calcium signals demonstrate that ON-MC LTD is expressed presynaptically and requires the activation of metabotropic glutamate receptors but does not require fast synaptic transmission. LTD at the $\mathrm{ON} \rightarrow \mathrm{MC}$ synapse is potentially relevant for the establishment, maintenance, and experience-dependent refinement of odor maps in the olfactory bulb.

Key words: calcium (Ca); imaging; olfactory; patch clamp; metabotropic glutamate receptor; plasticity; LTD

\section{Introduction}

The olfactory system detects and discriminates thousands of different odorant molecules in the environment, an ability that is critical for development and survival for many animals. In mammals, odor signals are converted into electrical signals by olfactory receptor neurons in the neuroepithelium of the nasal cavities. These receptor neurons express one or a small number of $\sim 1000$ olfactory receptor proteins (Chess et al., 1994; Serizawa et al., 2003), each of which binds odorants with particular molecular features. The axons of all of the 10,000-20,000 neurons expressing the same receptor protein converge onto a few (one to three) glomeruli (Vassar et al., 1994; Mombaerts et al., 1996), where they form synapses with the distally tufted single primary dendrites of mitral cells (MCs), with dendrites of tufted cells, and with periglomerular cells. The convergence of axons of sensory neurons expressing the same receptor onto topographically defined glomeruli creates a spatial map of the molecular features of the odor in the glomerular layer of the olfactory bulb (Vassar et al., 1994; Mombaerts et al., 1996; Wachowiak and Cohen, 2001). Glomerular "odor images" are reproducible within and across animals and are similar for similar odorant molecular structures (Wachowiak and Cohen, 2001; Takahashi et al., 2004). In rodents, odor maps are present soon after birth (Guthrie and Gall, 2003). Synaptogenesis between olfactory receptor neurons and MCs continues postnatally, suggesting that odor maps are likely refined during early postnatal development and by exposure to odorants from the environment (Guthrie and Gall, 2003). Post-

\footnotetext{
Received Nov. 18, 2004; revised March 17, 2005; accepted March 21, 2005.

We thank all members of the Knöpfel laboratory for many helpful discussions and encouragement, as well as Dr. R. Joho for comments on a previous version of this manuscript.

Correspondence should be addressed to Dr. Thomas Knöpfel, Laboratory for Neuronal Circuit Dynamics, Brain Science Institute, The Institute of Physical and Chemical Research (RIKEN), 2-1 Hirosawa, Wako-shi, Saitama 3510198, Japan. E-mail: tknopfel@brain.riken.jp.

DOI:10.1523/JNEUROSCI.4721-04.2005

Copyright $\odot 2005$ Society for Neuroscience $\quad$ 0270-6474/05/254252-08\$15.00/0
}

natal synaptogenesis is paralleled by synaptic regression of early formed synaptic contacts as MC dendrites develop a single apical dendrite from multiple immature dendritic processes into several adjacent glomeruli (Lin et al., 2000; Zou et al., 2004). Furthermore, axons from sensory neurons expressing different receptor types can initially intermingle and even mistarget in the glomerular layer, only gradually segregating and retracting to appropriate glomerular positions during the first postnatal days (Zou et al., 2004). Structural plasticity involving synaptic regression and circuit refinement has often been associated with functional plasticity. Indeed, behavioral and functional mapping experiments indicate functional plasticity at the level of olfactory glomeruli both during early odor preference learning and also in adult rodents (Yuan et al., 2002; Fletcher and Wilson, 2003; McLean and Harley, 2004). Despite these data on the system level, there has to date been little evidence for olfactory plasticity at the level of olfactory nerve $(\mathrm{ON}) \rightarrow \mathrm{MC}$ synapses except one report suggesting that $\mathrm{ON} \rightarrow \mathrm{MC}$ synapses can express long-term potentiation (LTP) (Ennis et al., 1998).

Here, we find that $\mathrm{ON} \rightarrow \mathrm{MC}$ synapses can express a longlasting depression of synaptic efficacy [referred to as ON-MC long-term depression (LTD)]. We use pharmacological and calcium imaging techniques to demonstrate that ON-MC LTD is expressed presynaptically and is mediated by metabotropic glutamate receptors (mGluRs). ON-MC LTD may provide a cellular model for the structural and behavioral plasticity and the dynamic maintenance of odor maps that occur at the level of $\mathrm{ON} \rightarrow \mathrm{MC}$ synapses.

\section{Materials and Methods}

Electrophysiology. The olfactory bulb was dissected from 5- to 8-d-old ICR mice. Horizontal slices (300-370 $\mu \mathrm{m}$ thick) were cut and recovered at $32^{\circ} \mathrm{C}$ for the first hour and then at room temperature $\left(23-25^{\circ} \mathrm{C}\right)$. After $>1$ h of recovery, a slice was transferred into the recording chamber and perfused with artificial CSF (ACSF) containing the following (in mM): 
A

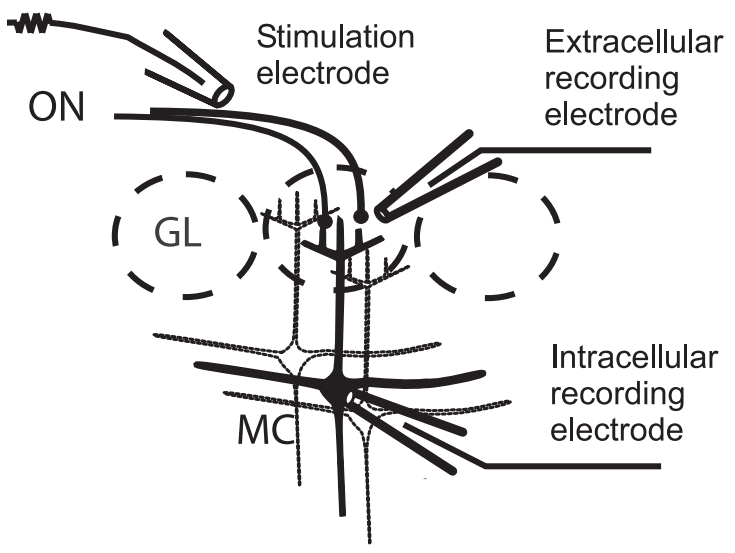

B1
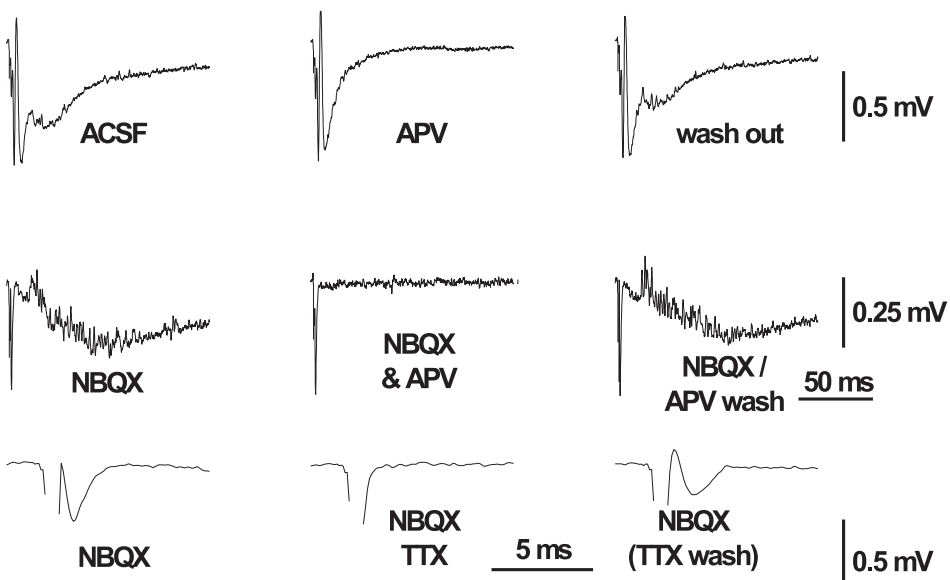

B2

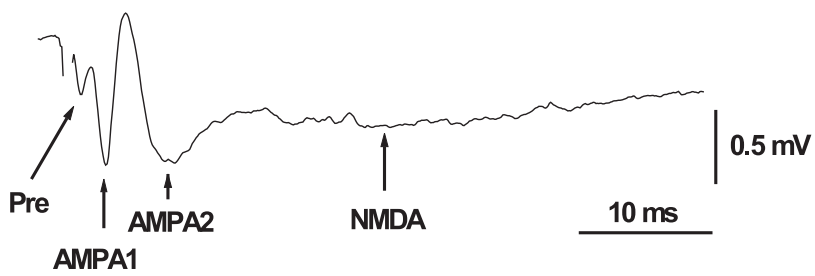

C
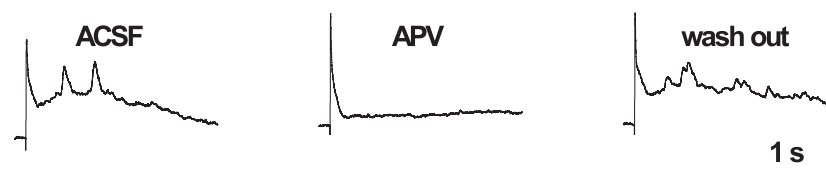

$10 \mathrm{mV}$
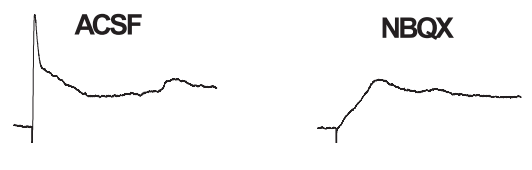

$200 \mathrm{~ms}$

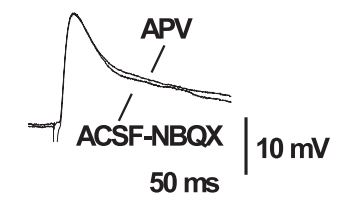

Figure 1. Synaptic responses evoked by $0 \mathrm{~N}$ stimulation in olfactory glomeruli and mitral cells. $\boldsymbol{A}$, Scheme of the recording configurations for glomerular field potentials, intracellular recordings from mitral cells, and stimulation of the olfactory nerve. $\mathrm{GL}$, Glomerular layer. $\boldsymbol{B}$, Glomerular field potentials (fEPSPS) evoked by ON stimulation. B1, The first and second rows show successive recordings in control saline (ACSF), after adding $50 \mu \mathrm{m}$ D-APV (APV), after washout of D-APV, after adding $20 \mu \mathrm{m}$ NBQX, after supplementing NBQX with D-APV, and after returning to NBQX (NBQX/APV wash). The third row shows the initial fEPSP component (note expanded time scale) in the presence of NBQX, after adding $1 \mu \mathrm{M}$ TTX, and after washout of TTX. B2, Allocation of fEPSP components to presynaptic action potentials (Pre), two AMPAR-mediated postsynaptic components (AMPA1 and AMPA2), and a slow NMDAR-mediated component (NMDA). C, EPSPs induced by test stimulus to ON and recorded from the soma of MCs. First row, Successive recordings in control saline (ACSF), after adding $50 \mu \mathrm{m}$ D-APV (APV), and after washout of D-APV. Second row, Recording in control ACSF and after adding $20 \mu \mathrm{M}$ NBQX (note expanded time scale). The traces to the right show superposition of an AMPAR-mediated EPSP recorded in D-APV and subtraction of the control recording by the recording in NBQX.
$118 \mathrm{NaCl}, 25 \mathrm{NaHCO}_{3}, 1 \mathrm{NaH}_{2} \mathrm{PO}_{4}, 3 \mathrm{KCl}, 1$ $\mathrm{MgCl}_{2}, 2 \mathrm{CaCl}_{2}$, and 10 glucose, equilibrated with $95 \% \mathrm{O}_{2}$ and $5 \% \mathrm{CO}_{2}$. Experiments were performed at room temperature $\left(23-25^{\circ} \mathrm{C}\right)$.

Field potentials were recorded in the glomerular layer with glass pipettes (filled with ACSF; 1.0-2.0 M $\Omega$ ). Patch-clamp recordings were performed in the whole-cell configuration. Glass pipettes (resistance, 3.5-4.5 $\mathrm{M} \Omega$ ) were pulled from borosilicate glass using a two-stage vertical puller (Narishige, Tokyo, Japan). Pipettes contained the following (in $\mathrm{mm}$ ): $9 \mathrm{KCl}$, $10 \mathrm{KOH}, 120 \mathrm{~K}$-gluconate, $3.48 \mathrm{MgCl}_{2}, 4 \mathrm{NaCl}, 10$ HEPES, 17.5 sucrose, $4 \mathrm{Na}_{2} \mathrm{ATP}$, and $0.4 \mathrm{Na}_{3} \mathrm{GTP}$, $\mathrm{pH}$ 7.25. In some recordings, the internal solution contained $3 \mathrm{~mm} \mathrm{~N}$-(2,6-dimethylphenylcarbamoylmethyl)triethylammonium bromide (QX-314) to block action potential generation. A $20 \mathrm{~mm}$ BAPTA-containing internal solution was made by replacing $80 \mathrm{~mm} \mathrm{~K}$-gluconate with 20 $\mathrm{mm} \mathrm{K}_{4}$-BAPTA. The osmolarity change was compensated for by addition of sucrose.

Constant-current stimulation pulses (5-100 $\mu \mathrm{A}, 300 \mu \mathrm{s}$ ) were applied to the ON layer using glass electrodes (filled with ACSF; 0.5-1.5 M 2 ). Test stimuli were delivered every $30 \mathrm{~s}$.

For each cell or slice, the peak amplitude of the evoked EPSPs or field EPSP (fEPSP) component was normalized to the mean response amplitude obtained during the baseline recording period. The amplitude of the NMDA receptor-mediated component of the fEPSP was measured at $20-30 \mathrm{~ms}$ after stimulation. Values are reported as percentage change from the mean of the baseline value. Population data are expressed as mean \pm SEM, where $n$ represents the number of experiments performed on different MCs (EPSPs) or slices (fEPSPs).

Calcium imaging. Mice [postnatal day 2 (P2)-P5] were anesthetized on ice. Olfactory receptor neurons in nasal cavities were exposed to $2 \mu \mathrm{l}$ of $0.25 \%$ Triton X-100 in physiological saline for $5 \mathrm{~min}$. Subsequently, nasal cavities were injected with $8 \mu \mathrm{l}$ of $4 \%$ Calcium Green-1 dextran (10 kDa; Molecular Probes, Eugene, $\mathrm{OR}$ ) in physiological saline, and mice were recovered from anesthesia. After 2-6 d, dyeinjected mice were used for slice preparation. Fluorescence of Calcium Green-1 was excited by epi-illumination $(480 \mathrm{~nm})$, with light provided by a monochromator (Polychrome IV; TILL Photonics, Gräfelfing, Germany) and detected by a cooled 12-bit charge-coupled device under control of TILL Vision (TILL Photonics) software. A filter set consisting of a dichroic beam splitter (DCLP 505 LP; Chroma Technology, Brattleboro, VT) and emission filter (535 \pm 25 $\mathrm{nm})$ was used. Fluorescence signals were converted to $\Delta F / F$ values, where $F$ is the baseline fluorescence and $\Delta F$ is the change in fluorescence. Color-coded maps of $\Delta F / F$ were prepared using custom-made macros under Image-Pro Plus (Media Cybernetics, Silver Spring, MD).

\section{Results}

\section{LTD at olfactory nerve synapses}

Field potential recordings and whole-cell patch-clamp recordings were made in hor- 
izontal olfactory bulb slices prepared from young mice (P5-P8). ON $\rightarrow$ MC synapses were activated by stimuli delivered via an electrode placed on the ON. fEPSPs were recorded with an electrode placed into an adjacent glomerulus, and EPSPs were recorded from the cell body of MCs with a patch-clamp electrode (Fig. 1A). Single ON stimuli induced glomerular fEPSPs that consisted of two distinct postsynaptic components. The first was pharmacologically identified as a slow NMDA receptor (NMDAR)-mediated component that was blocked by $50 \mu \mathrm{M}$ D-APV (Fig. 1B1,B2). The second was identified as an AMPA receptor (AMPAR)-mediated component that was blocked by $20 \mu \mathrm{M}$ 2,3-dioxo-6nitro-1,2,3,4-tetrahydrobenzo[f]quinoxaline-7-sulfonamide (NBQX) (Fig. 1B1) (Aroniadou-Anderjaska et al., 2000). The AMPAR-mediated fEPSP component consisted of an initial fast spike-like potential that most likely represents action potentials triggered by the ON-MC EPSP and a second slower potential (Fig. 1B2, AMPA1 and AMPA2, respectively). The initial deflection of the fEPSP was resistant to application of NBQX and D-APV but was abolished by TTX and, therefore, represents action potentials of the ON (Fig. 1B1,B2). ON-MC EPSPs exhibited corresponding pharmacological properties: a slow NMDAR-mediated component and a faster AMPAR-mediated component (Fig. 1C) (Aroniadou-Anderjaska et al., 2000).

After baseline recordings of ONinduced glomerular fEPSPs with test pulses applied every $30 \mathrm{~s}, 100$ stimulation pulses were delivered at $5 \mathrm{~Hz}$ and test pulse intensity. Return to the test stimulation frequency revealed a depression of glomerular fEPSPs that initially exceeded 50\% and then stabilized to a persistent depression of all postsynaptic fEPSP components (AMPA1 component, $92.3 \pm 2 \%$; AMPA2 component, $88.9 \pm 3 \%$; NMDA component, $87.1 \pm 3 \%$ of baseline values at $29-31$ min after tetanization; $n=10$ ). In contrast, the presynaptic component of the glomerular fEPSPs remained stable $(105 \pm 5 \%$ of baseline). Matching results were obtained when ON-MC EPSPs were tested (Fig. 2B). In these experiments, the internal solution contained 3 mM QX-314 to block action potential generation in MCs. Tetanization of the ON depressed all components of the ON-MC EPSPs (EPSP peak amplitude, $90.5 \pm 4 \%$ of baseline at $29-31 \mathrm{~min} ; n=13$ ).

To examine whether the $5 \mathrm{~Hz} / 100$ pulse stimulation protocol induced a saturating amount of ON-MC LTD, tetanic stimulation was applied twice with a $30 \mathrm{~min}$ interval (Fig. 3). The second tetanic stimulation did not induce further depression, demonstrating that saturation had occurred with the first tetanus. No-

B
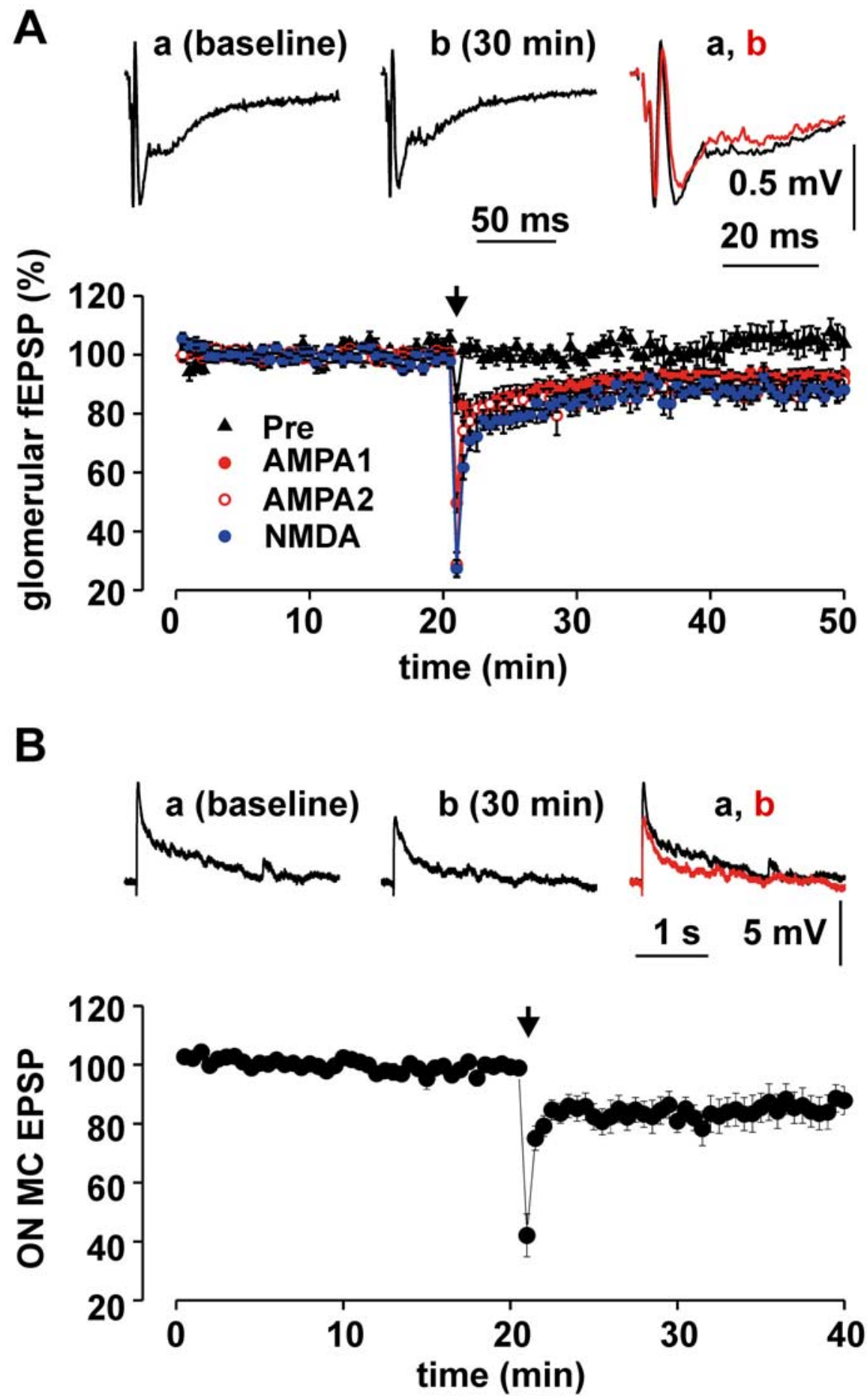

Figure 2. Tetanization induces long-term depression at ON synapses. $\boldsymbol{A}$, Top, Glomerular fEPSPs during baseline recording $(\boldsymbol{a})$ and $30 \mathrm{~min}$ after tetanization at $5 \mathrm{~Hz}$ for $20 \mathrm{~s}(\boldsymbol{b})$. Bottom, Time course of glomerular fEPSPs. In this and all following figures, time of tetanization is indicated by a downward arrow. Symbols represent values (mean $\pm \mathrm{SEM} ; n=10$ ) of the presynaptic component (Pre), AMPAR-mediated components (AMPA1 and AMPA2), and NMDAR-mediated component (NMDA). $\boldsymbol{B}$, Top, ON-MC EPSPs during baseline recording $(\boldsymbol{a})$ and 30 min after tetanization $(\boldsymbol{b})$. Bottom, Time course of EPSPs (mean \pm SEM; $n=13$ ).

tably, this experiment, along with the stable presynaptic signals in the fEPSP recordings, also demonstrated that the observed ON-MC LTD was not caused by deterioration of presynaptic or postsynaptic elements during tetanization. The depression of synaptic transmission induced by the $5 \mathrm{~Hz} / 100$ pulse stimulation lasted up to at least $2 \mathrm{~h}$, a duration that justifies the term ON-MC LTD. 


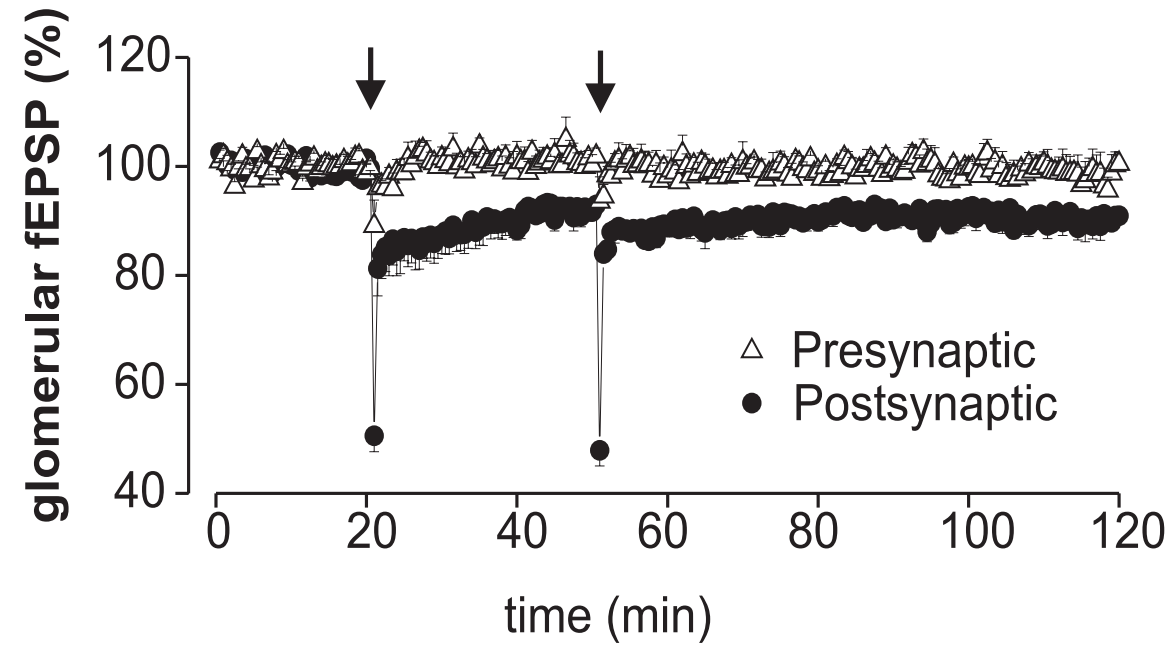

Figure 3. $\quad 0 N-M C L T D$ saturates. Time course of glomerular fEPSPs during two tetanizations (downward arrows) at an interval of $30 \mathrm{~min}$. Open triangles and filled circles represent values of presynaptic and AMPAR-mediated components, respectively (mean $\pm \mathrm{SEM} ; n=5$ ).
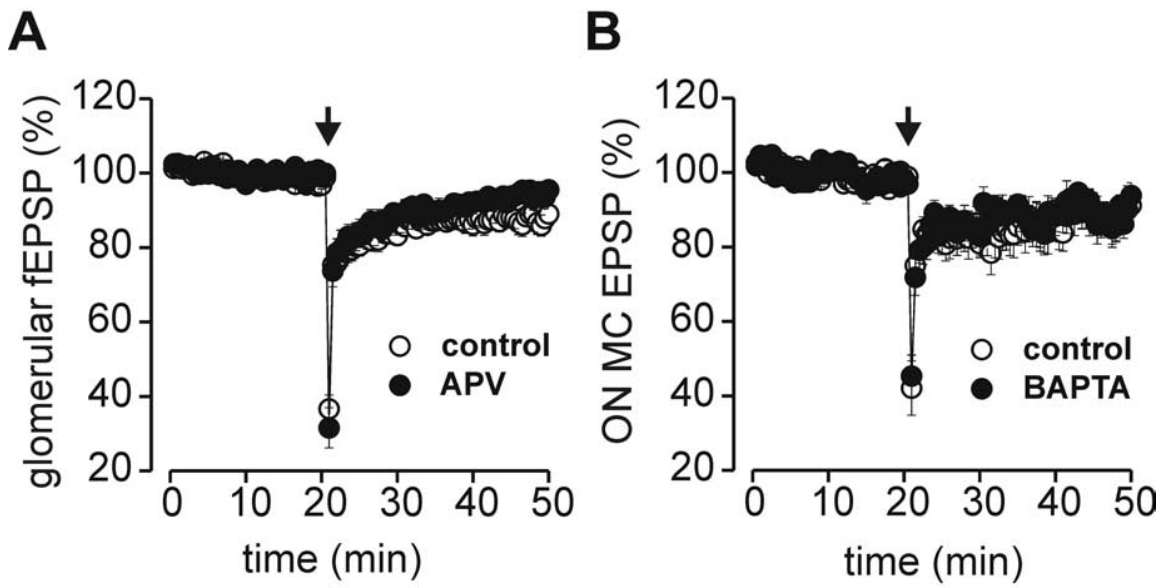

Figure 4. $\quad$ ON-MC LTD is not dependent on NMDAR and postsynaptic calcium signaling. $\boldsymbol{A}$, Time course of LTD of glomerular fEPSPs in control ACSF $(n=17)$ and in the presence of $50 \mu \mathrm{M} \mathrm{D}-\mathrm{APV}(\mathrm{APV} ; n=13)$. $\boldsymbol{B}$, Time course of ON-MCEPSs recorded with control patch pipette solution $(n=13)$ and with $20 \mathrm{~mm}$ BAPTA-containing pipettes $(n=10)$. The arrows represent the time of tetanization. Error bars represent SEM.

LTD at olfactory nerve synapses does not require activation of NMDA receptors or postsynaptic

calcium signaling

LTD at several synapses depends on the activation of NMDARs leading to postsynaptic $\mathrm{Ca}^{2+}$ elevation (Dudek and Bear, 1992; Lei and McBain, 2004; Liu et al., 2004). To test whether NMDAR activation is necessary for ON-MC LTD, tetanization was performed in the presence of $50 \mu \mathrm{M}$ D-APV (Fig. $4 A$ ). ON-MC LTD was not prevented by blockade of NMDAR (control, $87.3 \pm 3 \%$, $n=17$; D-APV, $91.9 \pm 2 \%, n=13$; percentage of baseline at $t=$ 20 min after tetanization). Postsynaptic $\mathrm{Ca}^{2+}$ elevation is prevented when the cell is loaded with the $\mathrm{Ca}^{2+}$ chelator BAPTA, a manipulation that blocks several forms of presynaptically and postsynaptically expressed LTD (Sakurai, 1990; Hansel and Linden, 2000; Lei and McBain, 2004). ON-MC LTD did not differ between cells recorded with $20 \mathrm{~mm}$ BAPTA-containing pipette solution and controls (control, $90.5 \pm 4 \%, n=13$; BAPTA, $91.3 \pm 4 \%, n=10$; percentage of baseline at $t=30 \mathrm{~min}$ ) (Fig. $4 B)$. The fact that postsynaptic $\mathrm{Ca}^{2+}$ elevation is not required for the induction of ON-MC LTD points toward a presynaptic mechanism.

LTD at olfactory nerve synapses is expressed presynaptically

One possible mechanism for presynaptically expressed LTD is the downregulation of voltage-dependent calcium channels that mediate glutamate release from $\mathrm{ON}$ terminals. To monitor presynaptic calcium signals in the ON, we applied the calcium indicator Calcium Green-1 dextran into the nasal cavities of P2-P5 mice (Wachowiak et al., 2000; Murphy and Isaacson, 2003). Two to six days later, these mice were used to prepare olfactory slices in which the ON fibers were selectively loaded with the calcium indicator. Figure $5 A$ shows a fluorescence image of an indicator-loaded slice with two stimulation electrodes placed onto the ON. Single stimulus to the $\mathrm{ON}$ induced calcium signals with amplitudes that were largest within the glomeruli underlying the tip of the activated stimulation electrode, suggesting a higher calcium channel density in olfactory receptor cell terminals than in their axons (Fig. 5A).

Figure $5 B$ illustrates an experiment in which ON-MC LTD was induced at one site, whereas a second site served as control. Induction of ON-MC LTD resulted in a marked depression of the $\mathrm{ON}$ calcium transient at the tetanized site; in contrast, the $\mathrm{Ca}^{2+}$ transient of the control site remained unchanged (Fig. 5B,C). On average, the depression of the calcium transient amounted to $18.6 \pm 5.8 \%$ of control values at $10-20 \mathrm{~min}$ after tetanus $(n=5$; controls, $3.5 \pm 2.8 \%, n=9$ ) (Fig. $5 D$ ). Interestingly, not only the amplitude but also the time course of the depression of the calcium transient closely matched that of the fEPSPs recorded in the same set of experiments (Fig. 5E).

These experiments clearly demonstrate a presynaptic mechanism for expression of ON-MC LTD that involves the downregulation of presynaptic calcium influx.

However, presynaptic expression of ON-MC LTD does not exclude the possible participation of postsynaptic activity. To test whether EPSPs are required for induction of ON-MC LTD, we tetanized the calcium-indicator loaded ON when synaptic transmission was also blocked by NBQX $(40 \mu \mathrm{M})$ and D-APV $(50 \mu \mathrm{M})$ and monitored the ON calcium signals. LTD of the presynaptic calcium transients was not affected by the blockade of fast synaptic transmission (no tetanization in control ACSF, 95.1 $\pm 2.2 \%$; no tetanization in NBQX and D-APV control, $99.3 \pm 1.5 \%$; tetanization in control ACSF, $84.1 \pm 3.8 \%$; tetanization in NBQX and D-APV, $82 \pm 2.8 \%$ of baseline at $14-18 \mathrm{~min}$ after tetanization; $n=6-7$ ) (Fig. $6 A$ ).

Next, we tested whether mGluRs might be involved in the induction of LTD. LTD of glomerular fEPSPs was antagonized by (S)-a-methyl-4-carboxyphenylglycine (MCPG), a prototypic 
mGluR antagonist (control, $92.0 \pm 2 \%$, $n=17$; MCPG, $97.9 \pm 1 \%, n=14$; percentage of baseline at $t=25 \mathrm{~min}$ ) (Fig. $6 B)$. Importantly, MCPG also antagonized LTD of the presynaptic calcium signals when ionotropic glutamate receptors were blocked by $40 \mu \mathrm{M}$ NBQX and $50 \mu \mathrm{M}$ D-APV (control, $83.7 \pm 3 \%, n=6$; MCPG, $95 \pm 4.2 \%$ of baseline at $t=10-18 \mathrm{~min}$ after tetanization, $n=5$ ) (Fig. $6 C$ ).

The above sets of experiments demonstrate a presynaptic expression mechanism of ON-MC LTD. Are the mGluRs that mediate induction of ON-MC LTD also localized presynaptically? If so, the mGluR1 that is expressed at high levels in olfactory glomeruli (Ferraguti et al., 1998; Heinbockel et al., 2004) would be the most obvious mGluR subtype to be considered. To test for functional expression of group I mGluRs in the ON terminals, we investigated the effect of (RS)-3,5dihydroxyphenylglycine (DHPG), a group I mGluR agonist, on ON calcium signals. Bath application of DHPG ( $50 \mu \mathrm{M}, 5 \mathrm{~min})$ in the presence of $40 \mu \mathrm{M}$ NBQX and $50 \mu \mathrm{M}$ D-APV reversibly decreased $\mathrm{ON}$ resting calcium levels (by $1.1 \pm 0.2 \%$ of baseline; $n=11$ ) (Fig. $7 A$ ), indicating functional expression of group I mGluR in the ON.

We next tested DHPG on ON stimulation-induced presynaptic $\mathrm{Ca}^{2+}$ transients (Fig. $7 B$ ). Bath application of DHPG $(100 \mu \mathrm{M})$ reduced ON stimulationinduced $\mathrm{Ca}^{2+}$ transients by $28 \pm 2.6 \%$ of baseline $(n=8$; at $t=30 \mathrm{~min}$ after DHPG application) and $\mathrm{ON}$ resting calcium levels by $1.3 \pm 0.5 \%$ of baseline ( $n=8$; peak response) (Fig. $7 B$ ). Importantly, the depression of the evoked presynaptic calcium transient was long lasting, whereas the effect on resting calcium concentration reversed after washout of DHPG. ON stimulation (in the absence of blockers of fast synaptic transmission) or DHPG application may lead to release of GABA and dopamine from juxtaglomerular cells, causing a component of the transient or lasting depression of ON signals. In fact, it is well known that both $\mathrm{GABA}_{\mathrm{B}}$ and dopamine $\mathrm{D}_{2}$ receptors mediate a (reversible) depression of ON-MC EPSPs via presynaptic mechanisms (Hsia et al., 1999; Ennis et al., 2001). To investigate a possible involvement of these receptors in ON-MC LTD, DHPG-induced depression of ON stimulation-induced presynaptic $\mathrm{Ca}^{2+}$ transients was tested in the presence of the $\mathrm{D}_{2}$ dopamine receptor antagonist sulpiride $(100 \mu \mathrm{M})$. Blockade of $\mathrm{D}_{2}$ receptors had no effect on the LTD of the presynaptic calcium signals (control, $73 \pm 4 \%, n=5$; sulpiride, $78 \pm 4 \%, n=5$ ) (Fig. 7C). LTD of ON fEPSP was also not affected in the presence of the $\mathrm{GABA}_{\mathrm{B}}$ antagonists saclofen (100 $\mu \mathrm{M} ; n=10$; data not shown) or CGP55845 [(2S)-3-[[(1S)-1(3,4-dichlorophenyl)ethyl] amino-2-hydroxypropyl] (phenylmethyl)phosphinic acid] ( $5 \mu \mathrm{M} ; n=15$; data not shown).

Finally, if DHPG induced LTD of the presynaptic calcium signals, we would expect ON-MC EPSPs to be expressed after direct activation of group I mGluRs. The results illustrated in Figure $7 D$ show that this is in fact the case. Application of DHPG (50 $\mu \mathrm{m}, 2 \mathrm{~min})$ resulted in a reversible depolarization
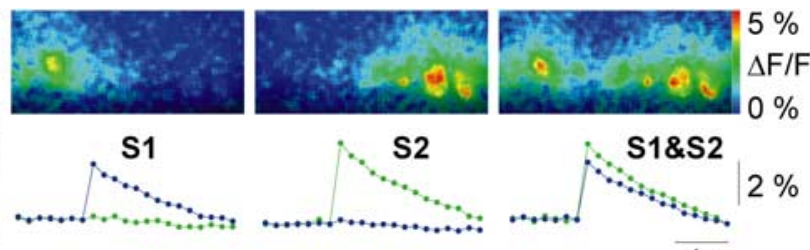

$1 \mathrm{~s}$
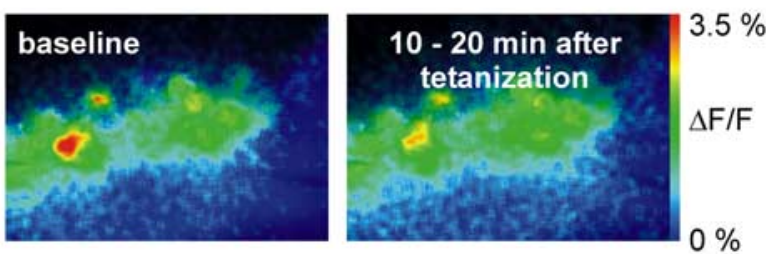

D

E
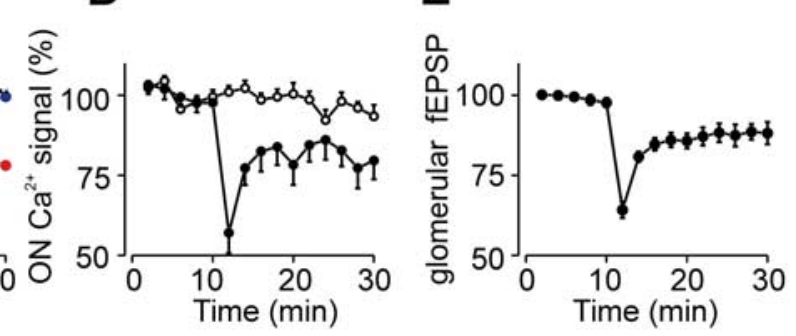

Figure 5. $\quad 0 \mathrm{~N}-\mathrm{MC}$ LTD reduces calcium transients in $0 \mathrm{~N}$ terminals. $\boldsymbol{A}$, Calcium signals in olfactory nerve terminals loaded with S2), and an outline of two regions of interest (ROI 1 and ROI 2). ONL, Olfactory nerve layer; GL, glomerular layer; EPL, external places show calcium signals induced in ROI 1 (blue symbols) and ROI 2 (green symbols) by stimuli delivered via tetanization of $\mathrm{S1}$ (right). C, Time course of $0 \mathrm{~N} \mathrm{Ca}^{2+}$ signals with test stimuli delivered to $\mathrm{S} 1$ and $\mathrm{S} 2$ and tetanization delivered to S1 from the experiment illustrated in $\boldsymbol{B}$. D. Pooled data of $0 \mathrm{NCa}^{2+}$ signals at tetanized (filled symbols; mean \pm SEM; $n=9$ ) and

$(5.6 \pm 1 \mathrm{mV} ; n=9)$ of the MCs and a lasting depression of EPSP amplitude (to $78 \pm 12 \%$ of baseline levels at $t=24 \mathrm{~min}$ after DHPG application; $n=4)$.

\section{Discussion}

We found that synapses formed between the ON and MCs can express LTD after a brief tetanic stimulation. We concluded that the expression of ON-MC LTD is presynaptically located based on the depression of presynaptic calcium transients after induction of ON-MC LTD and further substantiated by the ineffectiveness of manipulations that usually affect postsynaptic mechanisms (blockade of NMDA receptors, postsynaptic calcium buffering).

Is ON-MC LTD restricted to synapses at MCs, or do synapses formed between the $\mathrm{ON}$ and periglomerular or tufted cells also express LTD? We performed intracellular recordings only from MCs. These other cell types are also activated together with MCs after ON stimulation and may be involved in the generation of the fEPSPs. Because ON-MC LTD is presynaptically expressed, it is likely that $\mathrm{ON}$ synapses formed with periglomerular or tufted cells are also affected by ON-MC LTD. In the young animals used in this study, the number of periglomerular cells is smaller than in adults in which synaptic plasticity between the ON and periglomerular cells may be more significant. Indeed, preliminary experiments indicate that glomerular fEPSPs also express LTD in young adult mice (P20-P30; $n=3$; data not shown).

We did not systematically investigate whether stimulation 

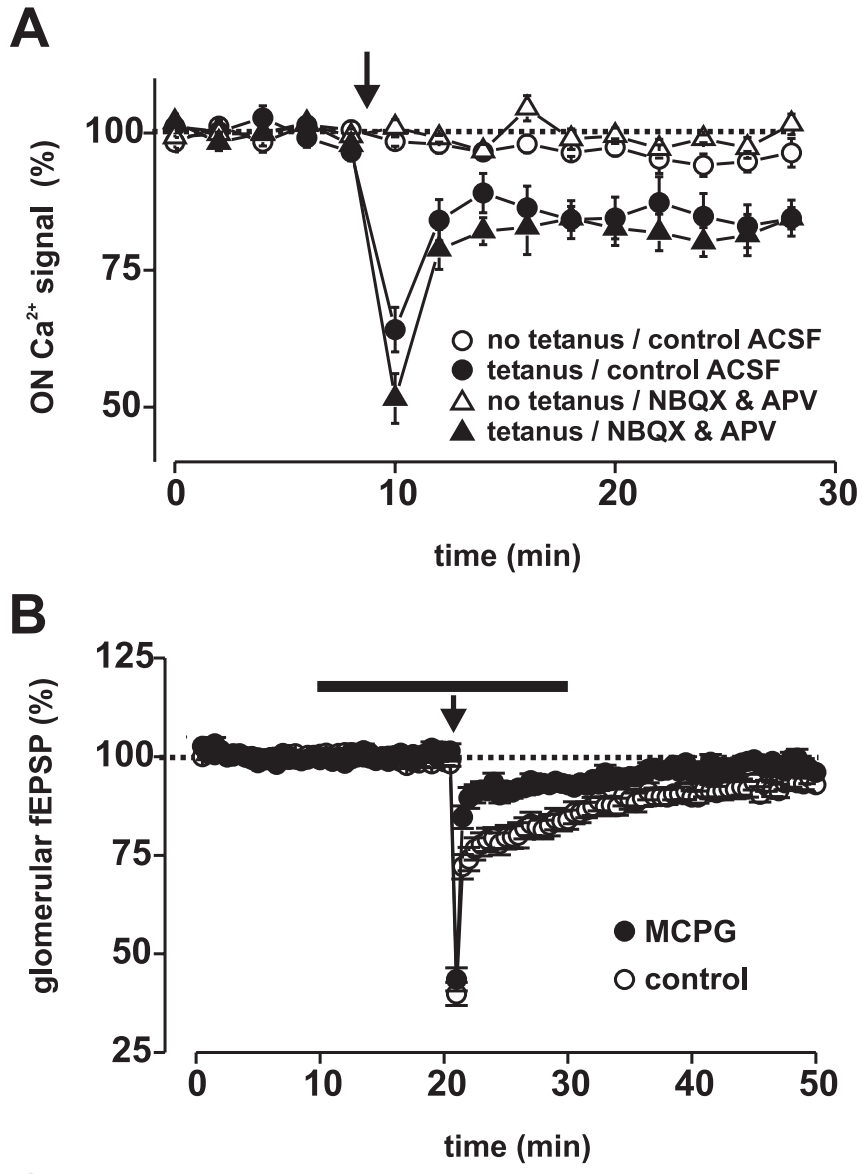

C

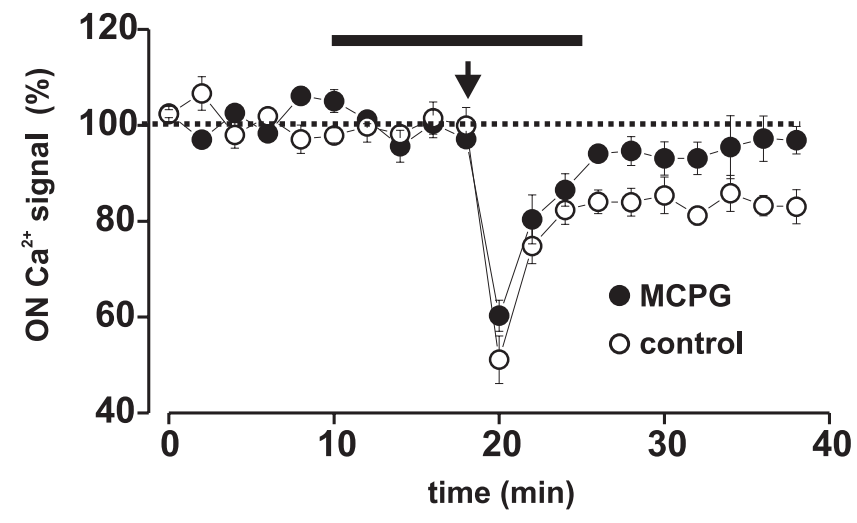

Figure 6. $\quad 0 N-M C L T D$ does not require activation of AMPA or NMDA receptors and is antagonized by the mGluR antagonist MCPG. $A$, Time course of $0 \mathrm{~N} \mathrm{Ca}^{2+}$ signals in control saline and in the presence of $40 \mu \mathrm{m} \mathrm{NBQX}$ and $50 \mu \mathrm{m}$ D-APV (APV) with and without tetanization. $B$, Bath application of $1 \mathrm{~mm} \mathrm{MCPG} \mathrm{(black} \mathrm{bar;} n=14$ ) had no effect on test fEPSPs but depressed the expression of $0 \mathrm{~N}-\mathrm{MC}$ LTD compared with control $(n=14)$. C, Bath application of $1 \mathrm{~mm} \mathrm{MCPG}$ (black bar; $n=14$ ) had no effect on baseline $\mathrm{Ca}^{2+}$ signals but depressed the reduction of the $0 \mathrm{~N} \mathrm{Ca}{ }^{2+}$ signals during $0 \mathrm{~N}-\mathrm{MCLTD}$ compared with control $(n=14)$. The arrows represent the time of tetanization. Error bars represent SEM.

protocols other than the 100 pulses at $5 \mathrm{~Hz}$ induce plasticity at $\mathrm{ON} \rightarrow \mathrm{MC}$ synapses. We only explored brief high-frequency stimulation (100 pulses at $100 \mathrm{~Hz})$, the most often used protocol for induction of LTP in the hippocampus. Our preliminary exploration (data not shown) suggested that high-frequency stimulation also induces LTD [rather than LTP as suggested in a previous report (Ennis et al., 1998)].
The observation that the degree of depression of presynaptic calcium transients was similar to that of postsynaptic signals was, at first glance, surprising. At many synapses in the CNS, the magnitude of presynaptic calcium transients is highly supra-linearly related to glutamate release following a power law with an exponent between three and four (Sabatini and Regehr, 1997; Murphy et al., 2004). This relationship would predict that $15 \%$ depression of the EPSP corresponds to only $4-5 \%$ reduction of the presynaptic calcium transient. However, it has been shown at synapses formed by the $\mathrm{ON}$ in olfactory glomeruli that the relationship between presynaptic calcium influx and glutamate release is almost linear (cooperativity coefficient, 1.5) (Murphy et al., 2004). High cooperativity increases the steepness of the relationship between the amplitude of the presynaptic calcium transient and transmitter release at calcium concentrations of the apparent dissociation constant. In contrast, relationships with low cooperativity render release probability more sensitive to variations in the amplitude of the calcium transient at calcium values that approach saturating levels under conditions of high cooperativity. The relationship between presynaptic calcium and probability of transmitter release is not known in detail for $\mathrm{ON} \rightarrow \mathrm{MC}$ synapses. The high release probability of $\mathrm{ON} \rightarrow$ MC synapses (Murphy et al., 2004) suggests, however, that they operate under conditions in which the low cooperativity of $\mathrm{Ca}^{2+}$ for triggering glutamate release may render them particularly sensitive to both short-term (Aroniadou-Anderjaska et al., 2000; Ennis et al., 2001; Murphy and Isaacson, 2003) and long-term (as described here) modulation of presynaptic calcium channel activity.

ON-MC LTD and LTD of evoked ON $\mathrm{Ca}^{2+}$ transients were antagonized by MCPG, an antagonist for mGluRs. Group I mGluRs, in particular the subtype mGluR1, are expressed at high levels in olfactory glomeruli (Ferraguti et al., 1998; Heinbockel et al., 2004), and the specific group I mGluR agonist DHPG induced a long-lasting depression of both evoked ON calcium transients and ON-MC EPSPs. In addition, DHPG induced a reversible reduction of $\mathrm{ON}$ resting $\mathrm{Ca}^{2+}$ concentration and a reversible depolarization of MCs. The mGluRs that mediate the transient and the lasting effects of DHPG and induction of ON-MC LTD could be localized at the $\mathrm{ON}$ as well as postsynaptically (Heinbockel et al., 2004). Our result that the group I mGluR agonist DHPG decreased $\mathrm{ON}$ resting $\mathrm{Ca}^{2+}$ concentration in the absence of fast synaptic transmission (Fig. 7A) and with $\mathrm{GABA}_{\mathrm{B}}$ and dopamine $\mathrm{D}_{2}$ receptors blocked (Fig. $7 C$ ) strongly indicates a functional expression of group I mGluRs at ON terminals. The decrease in presynaptic calcium concentration is in line with previous well documented systems in which group I mGluRs mediate a downregulation of calcium channel activity (Faas et al., 2002; Kitano et al., 2003).

The presence of presynaptic group I mGluRs and a presynaptic expression mechanism do not rule out the possibility that ON-MC LTD is mediated via postsynaptic mGluR and retrograde messengers, but the simplest model that is compatible with our data is that presynaptic mGluR1 involve in induction, whereas presynaptic calcium channels mediate expression of $\mathrm{ON}-\mathrm{MC}$ plasticity.

How does ON-MC LTD compare with other forms of LTD at central synapses? ON synapses resemble climbing fiber (CF) synapses at Purkinje cells with respect to their high release probability (Dittman and Regehr, 1998; Foster and Regehr, 2004; Murphy et al., 2004). CFs, like ON, express LTD (Hansel and Linden, 2000). CF-Purkinje cell LTD is also mGluR dependent, but, in contrast to ON-MC LTD, it is most likely mediated by postsynaptic changes (Hansel and Linden, 2000; Shen et al., 2002). Al- 
though downregulation of presynaptic $\mathrm{Ca}^{2+}$ channels is a classic target of shortterm receptor-mediated presynaptic inhibition (Miller, 1990), this mechanism has been linked previously to LTD only at a few synapses such as prelimbic cortex $\rightarrow$ nucleus accumbens synapses. LTD at these synapses is mediated by group II mGluRs (Robbe et al., 2002), whereas the ON and MCs of the main olfactory bulb express only low levels of group II mGluRs (Sahara et al., 2001), and our pharmacological data demonstrate that LTD of ON presynaptic calcium transients and of $\mathrm{ON} \rightarrow \mathrm{MC}$ synaptic transmission could be induced by direct activation of group I mGluRs. A DHPG-induced and presynaptically expressed form of LTD has been described in the CA1 region of hippocampal slices prepared from juvenile rats (Fitzjohn et al., 2001). However, there are also reports indicating postsynaptic induction and presynaptic expression mechanisms for the hippocampal DHPGinduced form of LTD (Watabe et al., 2002; Hou and Klann, 2004)

ON-MC LTD may be involved in early odor preference learning or central habituation (Wilson, 2000; Fletcher and Wilson, 2003; Yuan et al., 2003; Best and Wilson, 2004; McLean and Harley, 2004), but at present we have no positive evidence that would point in this direction. Electrophysiological mapping of MC activity has demonstrated an MC "odor output map" that differs from the ON "odor input map" in the tuning to specific odors that are represented by different glomeruli (Buonviso and Chaput, 1990; Mori et al., 1992; Yokoi, 1995; Luo and Katz, 2001). Activation of MC glomerular dendritic tufts, and hence MC output, depends on the balance between $\mathrm{ON}$ input and synaptic interactions between neighboring glomeruli (e.g., via short axon juxtaglomerular cells). It is therefore conceivable that ON-MC LTD shifts this balance toward a stronger influence of interglomerular interactions and thereby contributes to the difference between ON odor input map and MC odor output map (Buonviso and Chaput, 1990; Mori et al., 1992; Yokoi, 1995; Luo and Katz, 2001).

Additionally, ON-MC LTD may be involved in the establishment and maintenance of receptor cell-specific $\mathrm{ON}$ innervation of glomeruli. In young animals, there is considerable regression of ON fibers from aberrant innervations (Zou et al., 2004), and receptor cells are continuously replaced in animals of all ages (Schwob, 2002), a process that likely involves activity-dependent mechanisms.

Finally, whatever the natural conditions are under which ON-MC LTD occurs, plasticity at this synapse would implicate that glomerular odor images are, even at the level of the ON input, somehow less stable than generally assumed.

\section{References}

Aroniadou-Anderjaska V, Zhou FM, Priest CA, Ennis M, Shipley MT (2000)

Tonic and synaptically evoked presynaptic inhibition of sensory input to
B
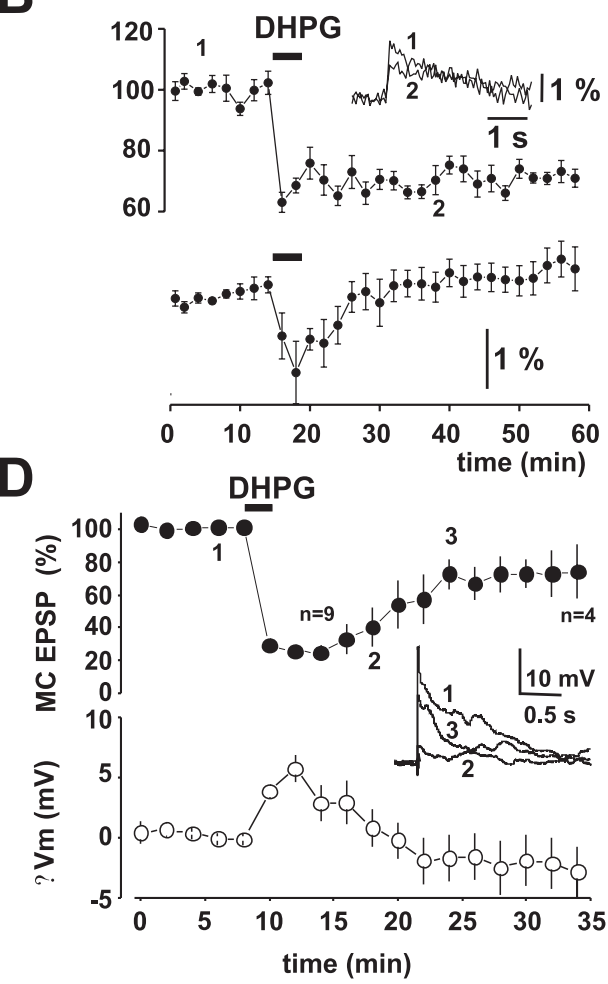

Figure 7. Induction of ON-MCLTD by direct activation of group I mGluRs and lack of requirement of $\mathrm{D}_{2}$ dopamine receptors. $\boldsymbol{A}$, Time course of $0 \mathrm{~N}$ resting $\mathrm{Ca}^{2+}$ concentration during bath application of the group I mGluR agonist DHPG in the continuous presence of $40 \mu \mathrm{m} \mathrm{NBQX}$ and $50 \mu \mathrm{m}$ D-APV (APV). Note that DHPG reversibly decreased resting $\mathrm{Ca}^{2+}$ concentration $(n=11)$. $\boldsymbol{B}$ (bottom trace) during bath application of $\mathrm{Ca}^{2+}$ concentration. The inset shows ON Ca ${ }^{2+}$ signals recorded before (1) and after (2) application of DHPG.C. Bath application EPSPs and transient depolarization of the MCs. The inset shows an ON-MC EPSP recorded before (1) and 8 min (2) and 15 min (3) after application of DHPG. Error bars represent SEM.

the rat olfactory bulb via GABA(B) heteroreceptors. J Neurophysiol 84:1194-1203.

Best AR, Wilson DA (2004) Coordinate synaptic mechanisms contributing to olfactory cortical adaptation. J Neurosci 24:652-660.

Buonviso N, Chaput MA (1990) Response similarity to odors in olfactory bulb output cells presumed to be connected to the same glomerulus: eletrophysiological study using simultaneous single-unit recordings. J Neurophysiol 63:447-454.

Chess A, Simon I, Cedar H, Axel R (1994) Allelic inactivation regulates olfactory receptor gene expression. Cell 78:823-834.

Dittman JS, Regehr WG (1998) Calcium dependence and recovery kinetics of presynaptic depression at the climbing fiber to Purkinje cell synapse. J Neurosci 18:6147-6162.

Dudek SM, Bear MF (1992) Homosynaptic long-term depression in area CA1 of hippocampus and effects of $N$-methyl-D-aspartate receptor blockade. Proc Natl Acad Sci USA 89:4363-4367.

Ennis M, Linster C, Aroniadou-Anderjaska V, Ciombor K, Shipley MT (1998) Glutamate and synaptic plasticity at mammalian primary olfactory synapses. Ann NY Acad Sci 855:457-466.

Ennis M, Zhou FM, Ciombor KJ, Aroniadou-Anderjaska V, Hayar A, Borrelli E, Zimmer LA, Margolis F, Shipley MT (2001) Dopamine D2 receptormediated presynaptic inhibition of olfactory nerve terminals. J Neurophysiol 86:2986-2997.

Faas GC, Adwanikar H, Gereau RW, Saggau P (2002) Modulation of presynaptic calcium transients by metabotropic glutamate receptor activation: a differential role in acute depression of synaptic transmission and long-term depression. J Neurosci 22:6885-6890.

Ferraguti F, Conquet F, Corti C, Grandes P, Kuhn R, Knöpfel T (1998) 
Immunohistochemical localization of the mGluRlbeta metabotropic glutamate receptor in the adult rodent forebrain: evidence for a differential distribution of mGluR1 splice variants. J Comp Neurol 400:391-407.

Fitzjohn SM, Palmer MJ, May JE, Neeson A, Morris SA, Collingridge GL (2001) A characterisation of long-term depression induced by metabotropic glutamate receptor activation in the rat hippocampus in vitro. J Physiol (Lond) 537:421-430.

Fletcher ML, Wilson DA (2003) Olfactory bulb mitral-tufted cell plasticity: odorant-specific tuning reflects previous odorant exposure. J Neurosci 23:6946-6955.

Foster KA, Regehr WG (2004) Variance-mean analysis in the presence of a rapid antagonist indicates vesicle depletion underlies depression at the climbing fiber synapse. Neuron 43:119-131.

Guthrie KM, Gall C (2003) Anatomic mapping of neuronal odor responses in the developing rat olfactory bulb. J Comp Neurol 455:56-71.

Hansel C, Linden DJ (2000) Long-term depression of the cerebellar climbing fiber-Purkinje neuron synapse. Neuron 26:473-482.

Heinbockel T, Heyward P, Conquet F, Ennis M (2004) Regulation of main olfactory bulb mitral cell excitability by metabotropic glutamate receptor mGluR1. J Neurophysiol 92:3085-3096.

Hou L, Klann E (2004) Activation of the phosphoinositide 3-kinase-Aktmammalian target of rapamycin signaling pathway is required for metabotropic glutamate receptor-dependent long-term depression. J Neurosci 24:6352-6361.

Hsia AY, Vincent JD, Lledo PM (1999) Dopamine depresses synaptic inputs into the olfactory bulb. J Neurophysiol 82:1082-1085.

Kitano J, Nishida M, Itsukaichi Y, Minami I, Ogawa M, Hirano T, Mori Y, Nakanishi S (2003) Direct interaction and functional coupling between metabotropic glutamate receptor subtype 1 and voltage-sensitive Cav2.1 Ca2+ channel. J Biol Chem 278:25101-25108.

Lei S, McBain CJ (2004) Two loci of expression for long-term depression at hippocampal mossy fiber-interneuron synapses. J Neurosci 24:2112-2121.

Lin DM, Wang F, Lowe G, Gold GH, Axel R, Ngai J, Brunet L (2000) Formation of precise connections in the olfactory bulb occurs in the absence of odorant-evoked neuronal activity. Neuron 26:69-80.

Liu L, Wong TP, Pozza MF, Lingenhoehl K, Wang Y, Sheng M, Auberson YP, Wang YT (2004) Role of NMDA receptor subtypes in governing the direction of hippocampal synaptic plasticity. Science 304:1021-1024.

Luo M, Katz LC (2001) Response correlation maps of neurons in the mammalian olfactory bulb. Neuron 32:1165-1179.

McLean JH, Harley CW (2004) Olfactory learning in the rat pup: a model that may permit visualization of a mammalian memory trace. NeuroReport 15:1691-1697.

Miller RJ (1990) Receptor-mediated regulation of calcium channels and neurotransmitter release. FASEB J 4:3291-3299.

Mombaerts P, Wang F, Dulac C, Chao SK, Nemes A, Mendelsohn M, Edmondson J, Axel R (1996) Visualizing an olfactory sensory map. Cell 87:675-686.

Mori K, Mataga N, Imamura K (1992) Differential specificities of single mitral cells in rabbit olfactory bulb for a homologous series of fatty acid odor molecules. J Neurophysiol 67:786-789.

Murphy GJ, Isaacson JS (2003) Presynaptic cyclic nucleotide-gated ion channels modulate neurotransmission in the mammalian olfactory bulb. Neuron 37:639-647.

Murphy GJ, Glickfeld LL, Balsen Z, Isaacson JS (2004) Sensory neuron signaling to the brain: properties of transmitter release from olfactory nerve terminals. J Neurosci 24:3023-3030.

Robbe D, Alonso G, Chaumont S, Bockaert J, Manzoni OJ (2002) Role of $\mathrm{P} / \mathrm{Q}-\mathrm{Ca}^{2+}$ channels in metabotropic glutamate receptor $2 / 3$-dependent presynaptic long-term depression at nucleus accumbens synapses. J Neurosci 22:4346-4356.

Sabatini BL, Regehr WG (1997) Control of neurotransmitter release by presynaptic waveform at the granule cell to Purkinje cell synapse. J Neurosci 17:3425-3435.

Sahara Y, Kubota T, Ichikawa M (2001) Cellular localization of metabotropic glutamate receptors mGluR1, 2/3, 5 and 7 in the main and accessory olfactory bulb of the rat. Neurosci Lett 312:59-62.

Sakurai M (1990) Calcium is an intracellular mediator of the climbing fiber in induction of cerebellar long-term depression. Proc Natl Acad Sci USA 87:3383-3385.

Schwob JE (2002) Neural regeneration and the peripheral olfactory system. Anat Rec 269:33-49.

Serizawa S, Miyamichi K, Nakatani H, Suzuki M, Saito M, Yoshihara Y, Sakano H (2003) Negative feedback regulation ensures the one receptor-one olfactory neuron rule in mouse. Science 302:2088-2094.

Shen Y, Hansel C, Linden DJ (2002) Glutamate release during LTD at cerebellar climbing fiber-Purkinje cell synapses. Nat Neurosci 5:725-726.

Takahashi YK, Kurosaki M, Hirono S, Mori K (2004) Topographic representation of odorant molecular features in the rat olfactory bulb. J Neurophysiol 92:2413-2427.

Vassar R, Chao SK, Sitcheran R, Nunez JM, Vosshall LB, Axel R (1994) Topographic organization of sensory projections to the olfactory bulb. Cell 79:981-991.

Wachowiak M, Cohen LB (2001) Representation of odorants by receptor neuron input to the mouse olfactory bulb. Neuron 32:723-735.

Wachowiak M, Zochowski M, Cohen LB, Falk CX (2000) The spatial representation of odors by olfactory receptor neuron input to the olfactory bulb is concentration invariant. Biol Bull 199:162-163.

Watabe AM, Carlisle HJ, O’Dell TJ (2002) Postsynaptic induction and presynaptic expression of group 1 mGluR-dependent LTD in the hippocampal CA1 region. J Neurophysiol 87:1395-1403.

Wilson DA (2000) Comparison of odor receptive field plasticity in the rat olfactory bulb and anterior piriform cortex. J Neurophysiol 84:3036-3042.

Yokoi M, Mori K, Nakanishi S (1995) Refinement of odor molecule tuning by dendrodendritic synaptic inhibition in the olfactory bulb. Proc Natl Acad Sci USA 92:3371-3375.

Yuan Q, Harley CW, McLean JH, Knöpfel T (2002) Optical imaging of odor preference memory in the rat olfactory bulb. J Neurophysiol 87:3156-3159.

Yuan Q, Harley CW, McLean JH (2003) Mitral cell betal and 5-HT2A receptor colocalization and cAMP coregulation: a new model of norepinephrine-induced learning in the olfactory bulb. Learn Mem 10:5-15.

Zou DJ, Feinstein P, Rivers AL, Mathews GA, Kim A, Greer CA, Mombaerts P, Firestein S (2004) Postnatal refinement of peripheral olfactory projections. Science 304:1976-1979. 